\title{
Viscosities of the crust and upper mantle constrained by three-dimensional GPS rates in the Sichuan-Yunnan fragment of China
}

\author{
Yawen She and Guangyu Fu*
}

\begin{abstract}
The plastic flow in the Sichuan-Yunnan fragment (SYF) is the consequence of the eastern expansion of the Tibetan Plateau. The SYF area can be divided into three sections by the Xiaojin River fault zone and Red River fault zone, which both contain the normal fault component, consistent with GPS observations. The average vertical rates of the three sections exhibit a step-like distribution, and the southern subsidence rate is about $1-2 \mathrm{~mm} /$ year with respect to the northern area. To explain the vertical movement in the SYF, we subtract the vertical rates caused by the horizontal movement from the observed vertical rates and then use a two-layer viscous model to constrain the viscosities of the crust and upper mantle in the SYF. The fitting results between the vertical observed and model data show that the viscosity of the upper mantle is about $2.8 \times 10^{22} \mathrm{~Pa}$ s and the viscosity of the crust is less than $1.0 \times 10^{25} \mathrm{~Pa}$ s. Furthermore, we find that the vertical tectonic stresses dominate the driving mechanism for the vertical movement in the SYF.
\end{abstract}

Keywords: Sichuan-Yunnan fragment (SYF), GPS rate field, Rheological isostatic adjustment model, Viscosities of the crust and upper mantle, Moho

\section{Introduction}

The Tibetan Plateau is one of the most complex tectonic areas on Earth. The collision between the Indian and Eurasian plates has created the Tibetan Plateau (e.g., Molnar and Tapponnier 1975; Patriat and Achache 1984; Tapponnier et al. 2001). Due to ongoing collision, the Tibetan Plateau is compressed in the north-south direction and extended in the east-west direction. However, the eastern movement of the Tibetan Plateau is obstructed by the rigid Sichuan Basin of the Yangtze Block, and in response, it turns southward to form a plastic flow that rotates clockwise around the Eastern Himalayan Syntaxis (e.g., Holt et al. 1991; Royden et al. 1997; Yin and Harrison 2000). As a result, the plastic flow reflecting the dynamic setting of the Tibetan Plateau occurs from north to south in the Sichuan-Yunnan fragment (SYF,

*Correspondence: fugy@cea-ies.ac.cn

Institute of Earthquake Forecasting, Earthquake Administration China, Beijing 100036, China red-dashed frame in Fig. 1), with some giant strike-slip faults accommodating the movement.

With the development of geodetic technology, the aforementioned dynamic process is also illustrated by geodetic observational data (Gan et al. 2007; Liang et al. 2013; Pan et al. 2018). Global positioning system (GPS) observation is an important geodetic tool in investigating the movement of the crust. It can show the tectonic movement of the Tibetan Plateau and its adjacent areas, like no other tool before. Recently, many studies have been conducted to explain the movements and deformations of the SYF area using GPS data. The GPS horizontal rate field has been studied by different researchers at different temporal scales, and they showed similar results as a whole (Gan et al. 2007; Hao et al. 2016; Liang et al. 2013; Pan et al. 2018). With the increase in the number of GPS stations and temporal scales, the horizontal deformations of this area are now more specifically presented. Compared to GPS horizontal rates in the SYF, the vertical rates are less discussed. Hao et al. (2016) used Gravity Recovery and Climate Experiment (GRACE) data to 


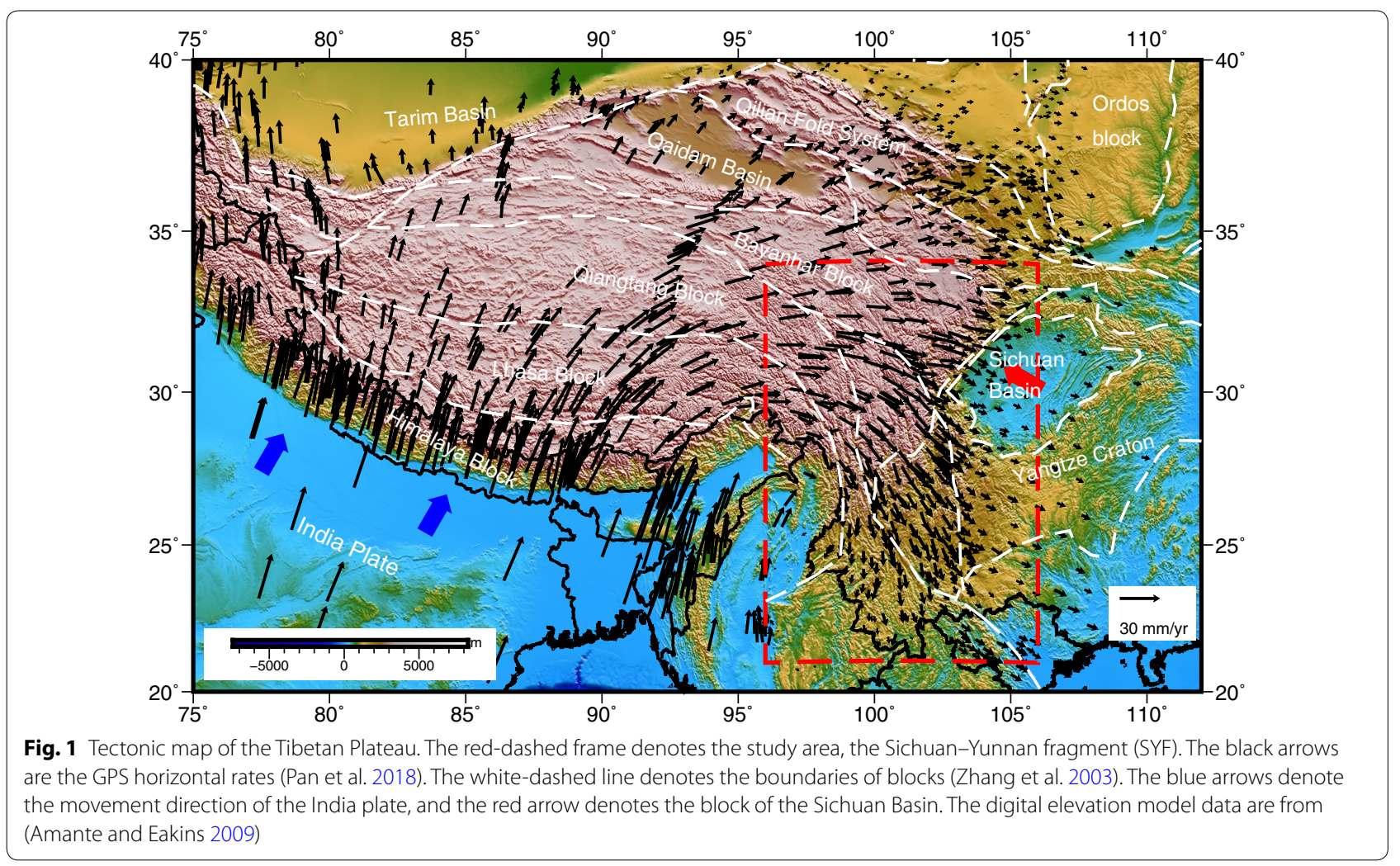

eliminate the seasonal variations from the GPS vertical data and presented the vertical rate field of the SYF. They found that the southern SYF subsides with respect to the northern SYF, and the subsidence (approximately $1-2 \mathrm{~mm} /$ year) cannot be explained by vertical rates (approximately $0.02 \mathrm{~mm}$ /year), which were transformed from GPS horizontal data with the assumption of uniform extension throughout the crust. The GPS vertical rates of such magnitude in the SYF have also been observed in other studies (Liang et al. 2013; Pan et al. 2018).

To explain the vertical movement of the SYF, we use an isostatic adjustment model of the lithosphere, consisting of the rheological crust and upper mantle, to simulate the vertical trend in the movement of the crust under vertical tectonic stresses (VTSs) and to constrain the viscosities of the crust and upper mantle.

\section{GPS data of the Sichuan-Yunnan fragment}

There are two primary features affecting the study of GPS vertical rates. First, the accuracy of GPS vertical data is presently not very high. Also, the observation results may be influenced by data processing strategies. With an increase in the data time span, the constraint from GRACE data and the corrections of the loading model, the present accuracy of GPS vertical rates can be improved to less than $1 \mathrm{~mm}$ /year (Hao et al. 2016; Pan et al. 2018), so the first question no longer applies in the study. For the second question, we used GPS data from different datasets to avoid this problem.

The vertical GPS dataset used here comes from three previous published studies: Hao et al. (2016), Liang et al. (2013) and Pan et al. (2018). Specifically, the dataset from Liang et al. (2013) contains continuous and campaign GPS data. Most of the campaign data have at least five observational campaigns, and the time span is over 10 years. The dataset of Hao et al. (2016) includes vertical rates from continuous GPS data over 6 years, beginning in mid-2010. Data from Pan et al. (2018) include both horizontal and vertical rates from continuous and campaign stations, and the time spans are greater than 6 years. The vertical rate fields of the three datasets are all relative to International Terrestrial Reference System (ITRF) 2008. Figure $2 \mathrm{a}-\mathrm{c}$ shows the vertical rates from the aforementioned three datasets. Considering that the overall pattern of the GPS vertical rates from the three datasets is similar, the signals are reliable, as a whole.

To minimize the effects of the different datasets on our study, we calculated the weighted average of the vertical rates of Hao et al. (2016) and Pan et al. (2018) for the same continuous observation stations with the observation error as the weight (Fig. 2d), for the use of 


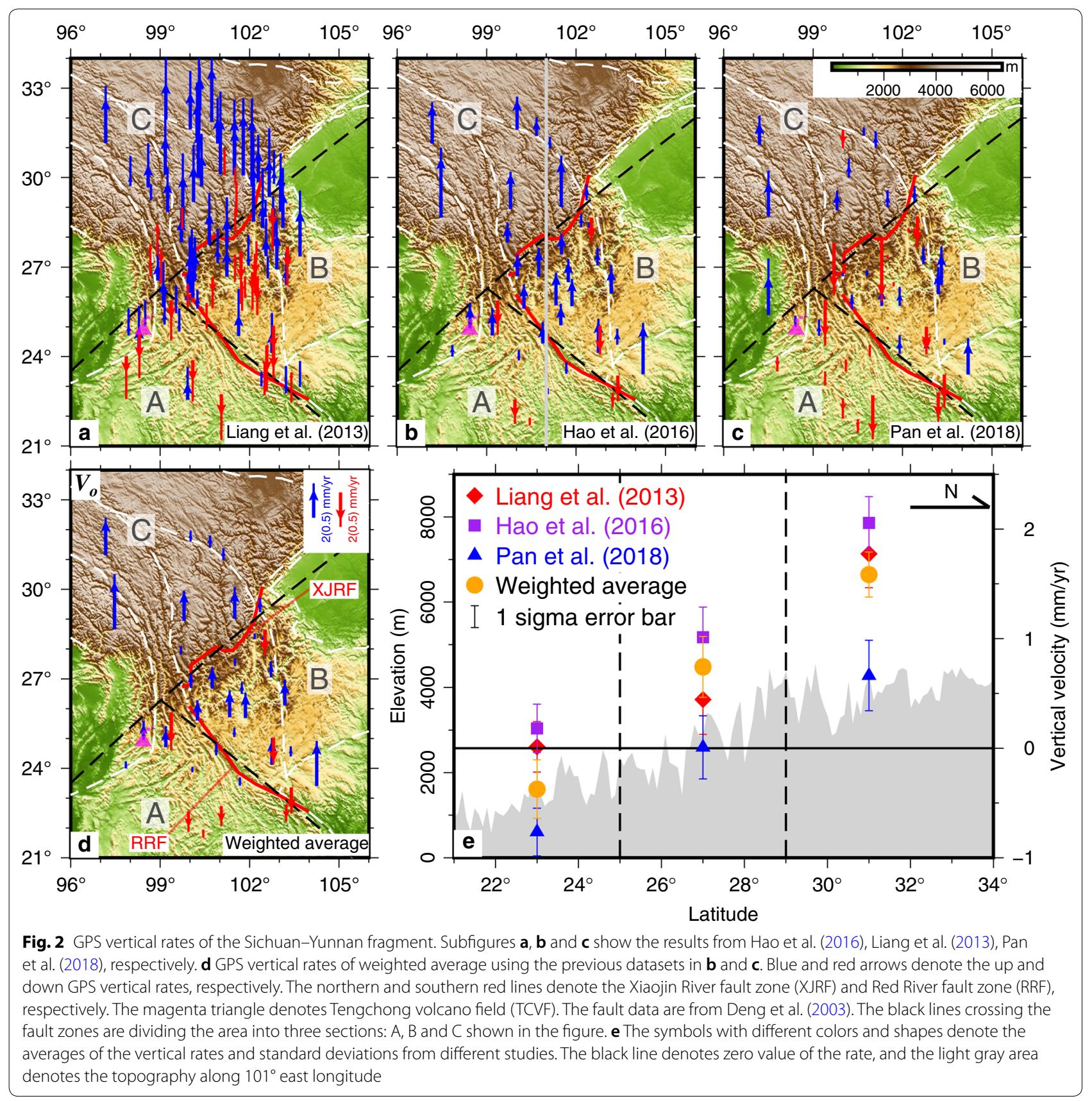

the subsequent calculations. Based on error propagation and weights, we calculate the standard deviation of the weighted average using the errors of the different data. Liang et al. (2013) do not give the vertical rates of these continuous stations and do not use GRACE data to correct GPS vertical rates. In contrast, Hao et al. (2016) and Pan et al. (2018) use GRACE data to correct the GPS vertical data. Thus, we excluded the data of Liang et al. (2013) from our averaging.
Furthermore, we use the XJRF and RRF (Fig. 2, red lines) to divide the area into A, B and $\mathrm{C}$ sections (Fig. 2), both containing the normal fault component, and the rates of the normal component of XJRF and RRF are about $0.5 \mathrm{~mm}$ /year and $1 \mathrm{~mm} /$ year (Wang et al. 2008), respectively. Then, the averages of the vertical rates of the three observational datasets and one weighted average dataset in A, B and C sections are calculated, respectively. The results (Fig. 2e) show that the average rates 
of the three sections exhibit a step-like distribution, and the step size is about $1 \mathrm{~mm} /$ year. Thus, the magnitude of the subsidence at the southern SYF is approximately $1-2 \mathrm{~mm} /$ year (Fig. 2e) with respect to the northern area for each dataset. As a result, we conclude that the subsidence of the southern SYF is reliable and is not a result of either data strategies or observation errors.

\section{Transformation between horizontal and vertical GPS rates}

Here, we assume that the observed GPS vertical rate $\left(V_{0}\right.$, the weighted average dataset described in the last section) includes two main contributions: the vertical rate resulting from the viscous isostatic adjustment of the lithosphere $\left(V_{\mathrm{c}}\right)$ and that transformed from horizontal tectonic movement $\left(V_{\mathrm{t}}\right)$. The main aim of this study is to obtain $V_{\mathrm{c}}$ using three-dimensional GPS data. Therefore, it is necessary to extract $V_{\mathrm{t}}$ from the horizontal GPS data.

First, we calculate the strain tensors of each GPS station using the least-squares collocation (LSC) method (Wu et al. 2011). Because the interpolation and extrapolation contain a priori information of the observation, it causes the LSC to be more reliable than the conventional method (Moritz 1980; She et al. 2016). As a result, the corresponding errors of the strain parameters can be determined from the posterior covariance matrix of the parameters and the covariance propagation law. Next, the aforementioned strain parameters are used to calculate the dilatational rates $\varepsilon_{\mathrm{h}}$ and then transform the horizontal strain $\varepsilon_{\mathrm{h}}$ into the vertical strain $\varepsilon_{\mathrm{V}}$ using the formula $\varepsilon_{\mathrm{v}}=-v \varepsilon_{\mathrm{h}}$. Here, $v$ denotes Poisson's ratio, and for the long-term problem, $v$ may take the value of 0.5 as incompressible fluid (e.g., Karner 1982; Nadai 1963; Walcott 1970). Finally, we obtain $V_{\mathrm{t}}$ by multiplying $\varepsilon_{\mathrm{v}}$ and the depth of the lithosphere-asthenosphere boundary (LAB) beneath the observation stations. The LAB divides the relatively rigid lid from the weaker mantle and represents the mechanical and chemical difference of the Earth's interior (Rychert and Shearer 2009). Thus, we use this depth to calculate the vertical rates by multiplying the vertical strain. The LAB data are from the LITHO 1.0 model (Pasyanos et al. 2014). It should be noted here that if we consider the effect of the isostatic adjustment, $V_{\mathrm{t}}$ will be much smaller than the result above. Therefore, the $V_{\mathrm{t}}$ calculated above should be the maximum estimate. Furthermore, we can obtain $V_{\mathrm{c}}$ easily using the formula $V_{\mathrm{c}}=V_{\mathrm{o}}-V_{\mathrm{t}}$

The Longmen Shan (LMS) and Eastern Himalayan Syntaxis (EHS) are the compressional areas, and the northern and middle areas are dilating. Figure $3 c$ shows the $V_{\mathrm{t}}$ at each continuous GPS station, which is transferred from the horizontal dilatational strains (Fig. 3b). Figure $3 \mathrm{~d}$ presents the vertical rates, which may be caused by the rheological isostatic adjustment $V_{\mathrm{c}}$. Note that the results presented in Fig. $3 \mathrm{~d}$ are based on the dataset of weighted average.

\section{Vertical tectonic stresses of the Sichuan-Yunnan fragment}

As described above, the vertical GPS rates cannot be explained by the horizontal compression; thus, we speculate that the VTSs exerted on the crust may be the source of the force causing the vertical movement recorded by the GPS. VTSs indicate the movement direction and stress state of the lithosphere due to its deviation from the isostatic state, for which positive and negative stresses indicate upward and downward forces, respectively ( $\mathrm{Fu}$ and She 2017; Gao et al. 2016; She et al. 2017). Following $\mathrm{Fu}$ and She (2017), the calculation formula of VTSs can be simply concluded as below:

$$
\sigma_{v}=-\left(\rho_{\mathrm{m}}-\rho_{\mathrm{c}}\right) g w-\left(\rho_{\mathrm{c}}-\rho_{\mathrm{f}}\right) g h .
$$

Herein, averaged $\rho_{\mathrm{c}}$ and $\rho_{\mathrm{m}}$ are the density of the Earth's crust and upper mantle, respectively. $\rho_{\mathrm{f}}$ denotes the density of the fill, and the value is set to 0 for the continental case and to $1020 \mathrm{~km} / \mathrm{m}^{3}$ for the ocean case (Chen et al. 2015; Kirby and Swain 2008; Watts 2001). $h$ and $w$ are the topography and Moho reliefs after removal of the average. $g$ is the gravity acceleration and set to $9.81 \mathrm{~m} / \mathrm{s}^{2}$.

The topography and density data extracted from ETOPO1 (Amante and Eakins 2009) and CRUST 1.0 (Laske et al. 2013) are used in Eq. (1) to calculate the VTSs of the SYF. The Moho data (Black contour in Fig. 4) deduced by Bouguer gravity data are from $\mathrm{Xu}$ et al. (2018). Note that VTSs are obtained by the primary density interface loads of the lithosphere including topography and Moho, so they have strong consistency with the topography and Moho (Fig. 4a). According to the distributions and scatters of the VTS and $V_{\mathrm{c}}$ Fig. 4a, b), the VTSs and $V_{\mathrm{c}}$ are generally consistent in the SYF area. Furthermore, the scatters of averages and standard deviation of the VTSs and $V_{\mathrm{c}}$ in the three sections (A, B and $\mathrm{C}$ in Fig. 4a) are calculated and shown in Fig. 4b, respectively. Both the VTSs and $V_{\mathrm{c}}$ show the step-like distribution between the three parts divided by XJRF and RRF. Thus, it is reasonable to speculate that the VTSs may be the cause of the subsidence of the southern SYF, observed by GPS.

However, some scatters (Fig. 4b, red squares) fall into the second and fourth quadrants in Fig. 4b, which means the orientations of $V_{\mathrm{c}}$ and VTSs are opposite. These scatters mainly distribute in the southern area of the SYF (Fig. 4a, red squares). The scatters around TCVF may be affected by deep material migration. For the other scatters, we speculate that the Moho data may cause the disagreement due to their low accuracy. Because in 


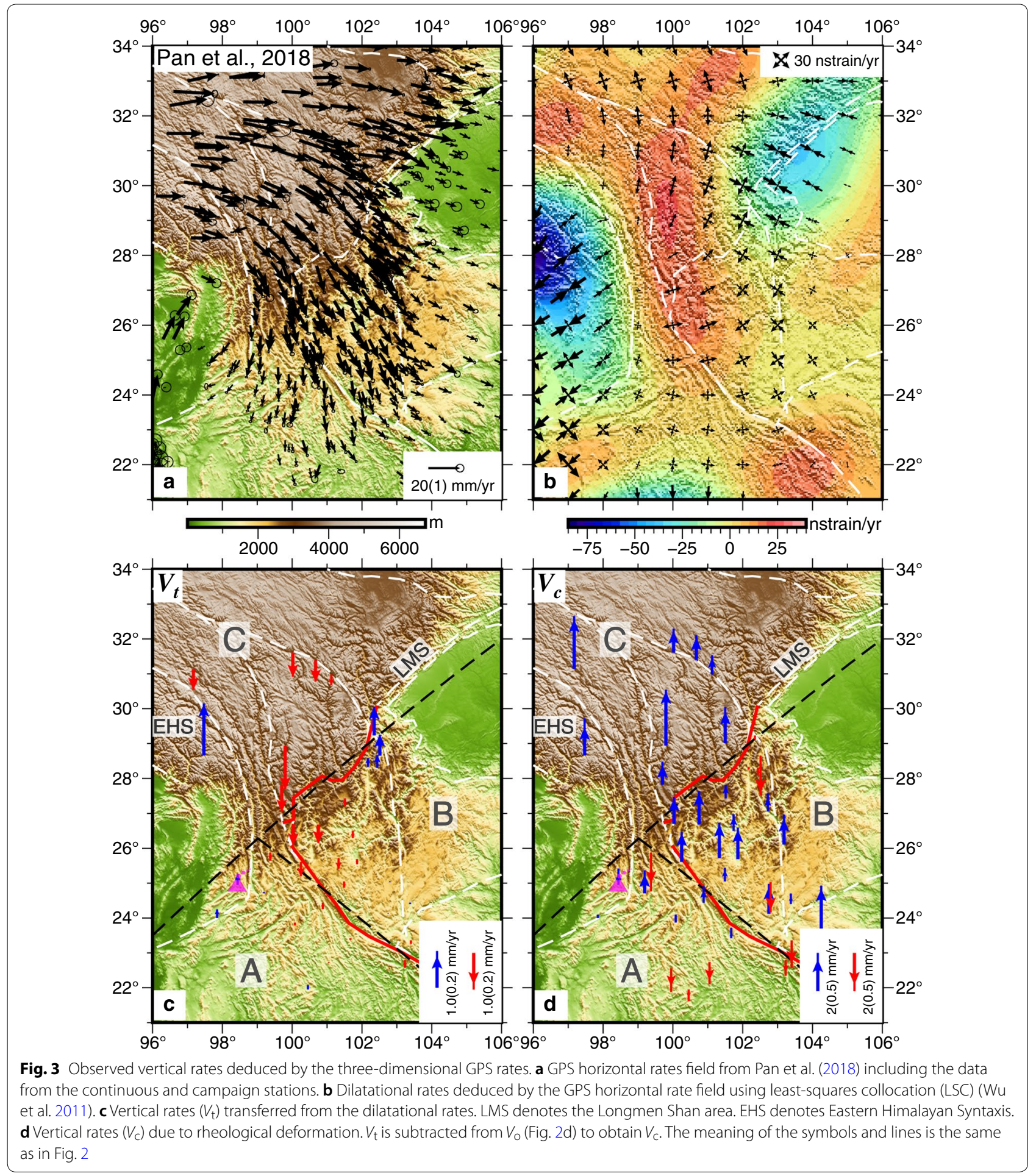

comparison with the observed topographic data, the Moho surface data are obtained by the inversion. Nonetheless, the linear distribution of $V_{\mathrm{c}}$ and VTSs verifies our speculation that the VTSs cause the vertical rates in the study area. Most of the scatters in the second and fourth quadrants are close to the origin, and only a few points have large values. These scatters do not significantly change the linear distribution of all the scatters. Thus, we will not remove the corresponding points from the $V_{\mathrm{c}}$. 


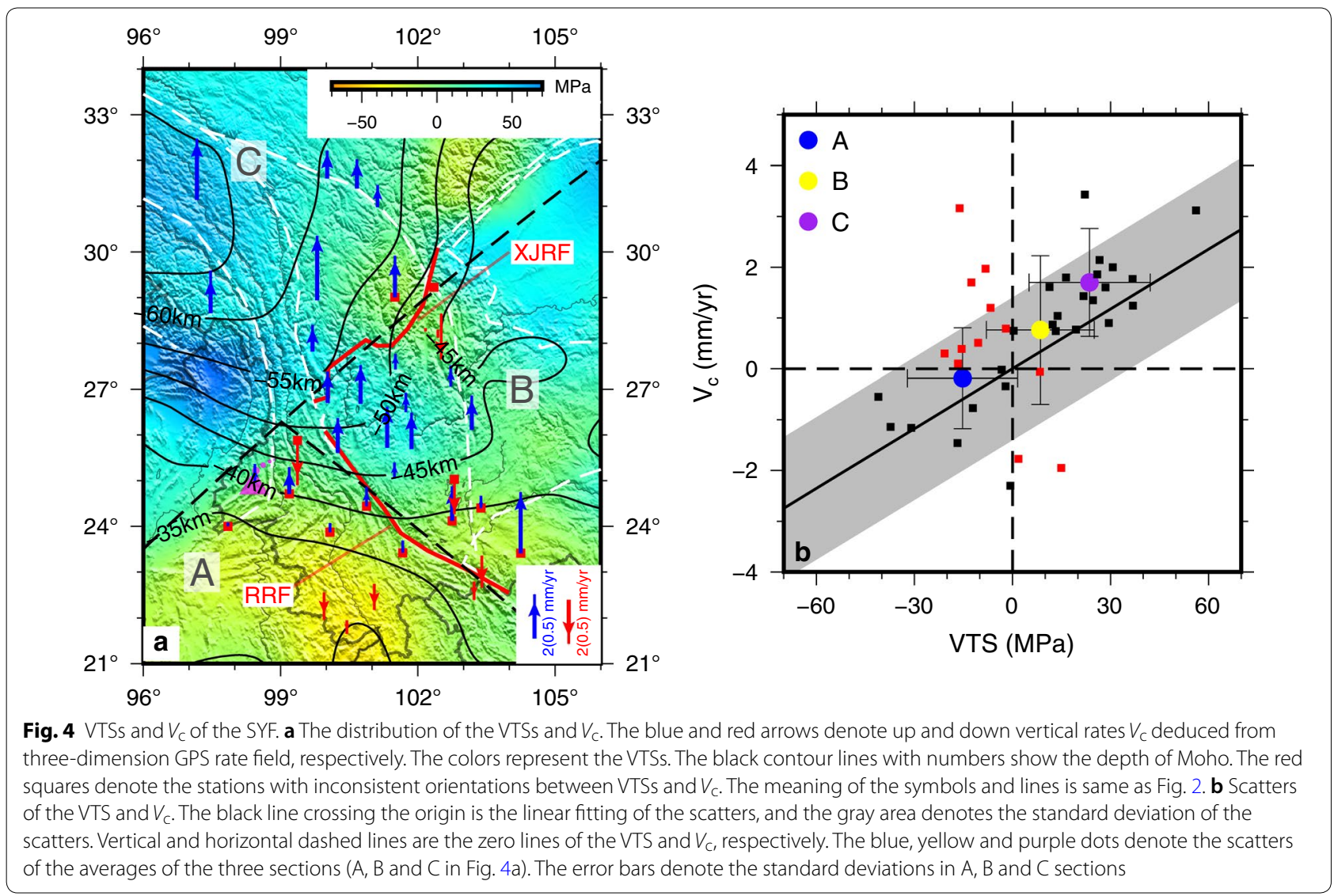

\section{Viscous flexure model}

Here, we use a Newtonian viscous plate (crust) floating on a gravitating and heavily viscous substratum (upper mantle) to simulate the vertical movement of the lithosphere under the VTSs. The differential equation is given by (Nadai 1963), and we adopt the equation to this study as below:

$$
\begin{aligned}
& N \nabla^{4} \dot{d}+\left(\rho_{\mathrm{m}}-\rho_{\mathrm{f}}\right) g d+\eta_{\mathrm{m}} \nabla \dot{d} \\
& \quad=-\left(\rho_{\mathrm{m}}-\rho_{\mathrm{c}}\right) g w-\left(\rho_{\mathrm{c}}-\rho_{\mathrm{f}}\right) g h .
\end{aligned}
$$

Combining Eqs. (1) and (2), it is easy to conclude that $d$ represents the vertical deformation caused by the VTSs and is the function of time and spatial position. The parameter $\dot{d}$ is the time derivative, and $N$ is the viscous modulus of the Earth's crust. The parameter $\eta_{\mathrm{m}}$ is the viscosity of the Earth's upper mantle. A similar formula is also given by Kirby and Swain (2009) for an elastic model. According to Nadai (1963) for the incompressible case, the expression of $N$ is:

$$
N=\frac{\eta_{\mathrm{c}} T^{3}}{3},
$$

where $\eta_{\mathrm{c}}$ and $T$ are the viscosity and thickness of the Earth's crust, respectively. Here, we take the averaged thickness of the crust in the study area as the value of $T$, and the data are extracted from CRUST 1.0.

To solve Eq. (2), we perform a two-dimensional Fourier transform on both sides of the differential equation, and the results can be expressed as below:

$$
\begin{aligned}
& N k^{4} \dot{D}+\left(\rho_{\mathrm{m}}-\rho_{\mathrm{f}}\right) g D+\eta_{\mathrm{m}} k \dot{D} \\
& \quad=-\left(\rho_{\mathrm{c}}-\rho_{\mathrm{f}}\right) g H-\left(\rho_{\mathrm{m}}-\rho_{\mathrm{c}}\right) g W .
\end{aligned}
$$

Herein $H, W$ and $D$ are the spectral-domain expressions of $h, w$ and $d$ of the spatial domain, respectively. $D$ is a function of time $t$ and wave number $k$, which equals $2 \pi / \lambda$, where $\lambda$ is the wavelength of the relief of the topography and Moho. For the viscous crust and upper mantle model, when $t$ is equal to zero, the flexure deformation should also be zero. With the boundary condition above the solution of Eq. (4) is:

$$
D=-\frac{\left(\rho_{\mathrm{m}}-\rho_{\mathrm{c}}\right) W+\left(\rho_{\mathrm{c}}-\rho_{\mathrm{f}}\right) H}{\rho_{\mathrm{m}}-\rho_{\mathrm{f}}}\left(1-\mathrm{e}^{-\frac{\left(\rho_{\mathrm{m}}-\rho_{\mathrm{f}}\right) g t}{N k^{4}+\eta_{\mathrm{m}} k}}\right) .
$$


Furthermore, the vertical rates $\dot{D}$ of spectral domain can be given by differentiating Eq. (5) with $t$ to obtain the expression as:

$$
\dot{D}=-\frac{\left(\rho_{\mathrm{m}}-\rho_{\mathrm{c}}\right) g W+\left(\rho_{\mathrm{c}}-\rho_{\mathrm{f}}\right) g H}{N k^{4}+\eta_{\mathrm{m}} k} \mathrm{e}^{-\frac{\left(\rho_{\mathrm{m}}-\rho_{\mathrm{f}}\right) g t}{N k^{4}+\eta_{\mathrm{m}} k}} .
$$

Based on Eq. (5), it is easy to obtain

$$
\left\{\begin{array}{ll}
D=0, & t=0 \\
D=-\frac{\left(\rho_{\mathrm{c}}-\rho_{\mathrm{f}}\right) H+\left(\rho_{\mathrm{m}}-\rho_{\mathrm{c}}\right) W}{\rho_{\mathrm{m}}-\rho_{\mathrm{f}}}, & t=\infty
\end{array} .\right.
$$

Equations (5) and (7) represent the physical meaning of the model. Specifically, when $t$ is equal to zero, there is no flexure deformation. When time is greater than zero, the flexure deformation $D$ depends on the $\eta_{\mathrm{c}}$ and $\eta_{\mathrm{m}}$ while the other parameters are determined by CRUST1.0. For the case of unlimited time, $D$ is the status of plastic deformation, the Airy isostasy.

The $d$ and $\dot{d}$ (hereinafter expressed as $V_{\mathrm{m}}$ ) are obtained by performing the inverse Fourier transform on Eqs. (5) and (6), respectively. Using the model above, we can calculate $V_{\mathrm{m}}$ at any time with different $\eta_{\mathrm{c}}$ and $\eta_{\mathrm{m}}$. Furthermore, we calculate $V_{\mathrm{m}}$ from 1 to 1000 years with same parameters, which is consistent with the rates of the first year. Thus, this model provides stable vertical rates, and we use the rates for the first year as the modeled vertical rates $V_{\mathrm{m}}$.

\section{Viscosities of crust and upper mantle in the Sichuan-Yunnan fragment}

In this section, we will fit the $V_{\mathrm{c}}$ by using the $V_{\mathrm{m}}$ described in the previous section to constrain the $\eta_{\mathrm{c}}$ and $\eta_{\mathrm{m}}$. Here, we adopt the global search method to find the minimum of the misfit, and the objective function is expressed as below [Eq. (8)]:

$$
H_{\eta}=\left[\frac{1}{n} \sum_{1}^{n}\left(\frac{V_{\mathrm{c}}-V_{\mathrm{m}}\left(\eta_{\mathrm{c}}, \eta_{\mathrm{m}}\right)}{\Delta V}\right)^{2}\right]^{\frac{1}{2}} .
$$

Herein, $H_{\eta}$ is the misfit, $n$ is the number of $V_{\mathrm{c}}$ and $\Delta V$ is the error of $V_{\mathrm{c}}$.

The rock deformation experiment shows that $\eta_{\mathrm{c}}$ is in the magnitude range of $10^{18}-10^{28} \mathrm{~Pa}$ (Strehlau and Meissner 1987), in which the lower limit is consistent with the viscosity of the lower crustal flow $10^{18}-10^{19}$ Pa s (Clark and Royden 2000; Lu et al. 2017; Royden et al. 1997, 2008), and the upper limit is greater than the viscosity of the entire lithosphere, $10^{21}-10^{24} \mathrm{~Pa}$ s in Tibetan Plateau (England and Molnar 1997; Flesch et al. 2001). Shoreline data show that the magnitude range of $\eta_{\mathrm{c}}$ is $10^{20}-10^{26} \mathrm{~Pa}$ s (Bills et al. 1994). In summary, it is reasonable to set the search range of $\eta_{\mathrm{c}}$ to $10^{18}-10^{28} \mathrm{~Pa}$.
The globally averaged viscosity of the upper mantle is in the magnitude range of $10^{20}-10^{21} \mathrm{~Pa}$ (Lau et al. 2016; Mitrovica and Forte 1997; Peltier 1998). However, $\eta_{\mathrm{m}}$ varies greatly from $10^{17}-10^{21} \mathrm{~Pa}$ at different regions and depths with different models (Bürgmann and Dresen 2008; Dixon et al. 2004). Leveling and GPS data in the areas with a relative thin crust show that $\eta_{\mathrm{m}}$ is in the magnitude range of $10^{17}-10^{19} \mathrm{Pas}$ at depths less than 50 km (Bills et al. 1994; Kaufmann and Amelung 2000; Pollitz 2003; Yamagiwa et al. 2015). Relative sea-level curves from shoreline elevation and GPS data show that $\eta_{\mathrm{m}}$ is in the magnitude range of $10^{19}-10^{22} \mathrm{~Pa}$ at depths more than $100 \mathrm{~km}$ (Bills et al. 1994; Lambeck et al. 1998; Lau et al. 2016; Milne et al. 2001, 2004; Mitrovica and Forte 1997; Peltier 1998). In summary, it is reasonable to set the search range of $\eta_{\mathrm{m}}$ to $10^{17}-10^{22} \mathrm{~Pa}$.

The optimal result of the global search reveals $\eta_{c}$ and $\eta_{\mathrm{m}}$ values of $4.0 \times 10^{23} \mathrm{Pas}$ and $2.8 \times 10^{22} \mathrm{~Pa} \mathrm{~s}$, respectively (Fig. 5c: the cross of the black dashed line). The $V_{\mathrm{m}}$ (Fig. 5b) of the optimal result is generally consistent with $V_{\mathrm{c}}$ (Fig. 5a). The value of $\eta_{\mathrm{m}}$ is about one order of magnitude larger than the average $\eta_{\mathrm{m}}\left(10^{21} \mathrm{~Pa}\right)$ and is close to the viscosity of lower mantle $\left(10^{22} \mathrm{Pas}\right)$ (Lau et al. 2016; Milne et al. 2004; Peltier et al. 2015). The value of $\eta_{\mathrm{c}}$ is close to the upper limit of the lithosphere in the SYF (Flesch et al. 2001). However, the distribution of the misfit shows that the fitting result of $\eta_{\mathrm{c}}$ is not unique (Fig. 5c). Specifically, the misfit is very close to the minimum when $\eta_{\mathrm{c}}$ is in the range of $10^{18}-10^{25} \mathrm{~Pa}$ s. Thus, the upper limit of $\eta_{\mathrm{c}}$ is about $1.0 \times 10^{25} \mathrm{~Pa}$ and the lower limit of $\eta_{\mathrm{c}}$ cannot be determined in this study. The weak constraint of $\eta_{\mathrm{c}}$ may be caused by the distribution of the stations and the heterogeneity of the crust.

\section{Discussion}

The model used in this work consists of two viscous layers, the crust with a relatively high-viscosity floating on the upper mantle with a low viscosity. The driving force (VTSs) is generated by the deviation of the topography and Moho from the isostatic state. Thus, other forces acting on the surface and deep lithosphere may have an impact on our research.

\section{Vertical motion caused by surface mass migration}

On the surface, mass migration mainly includes deposition, erosion and water storage change, which may lead to vertical movement. However, these effects contained in the GPS data used in this study are already eliminated by using Gravity Recovery and Climate Experiment (GRACE) mission data, and the effect of mass migration on vertical rates $\left(V_{g}\right)$ is about $0.1 \mathrm{~mm} /$ year (Hao et al. 2016; Pan et al. 2018) in the SYF. 


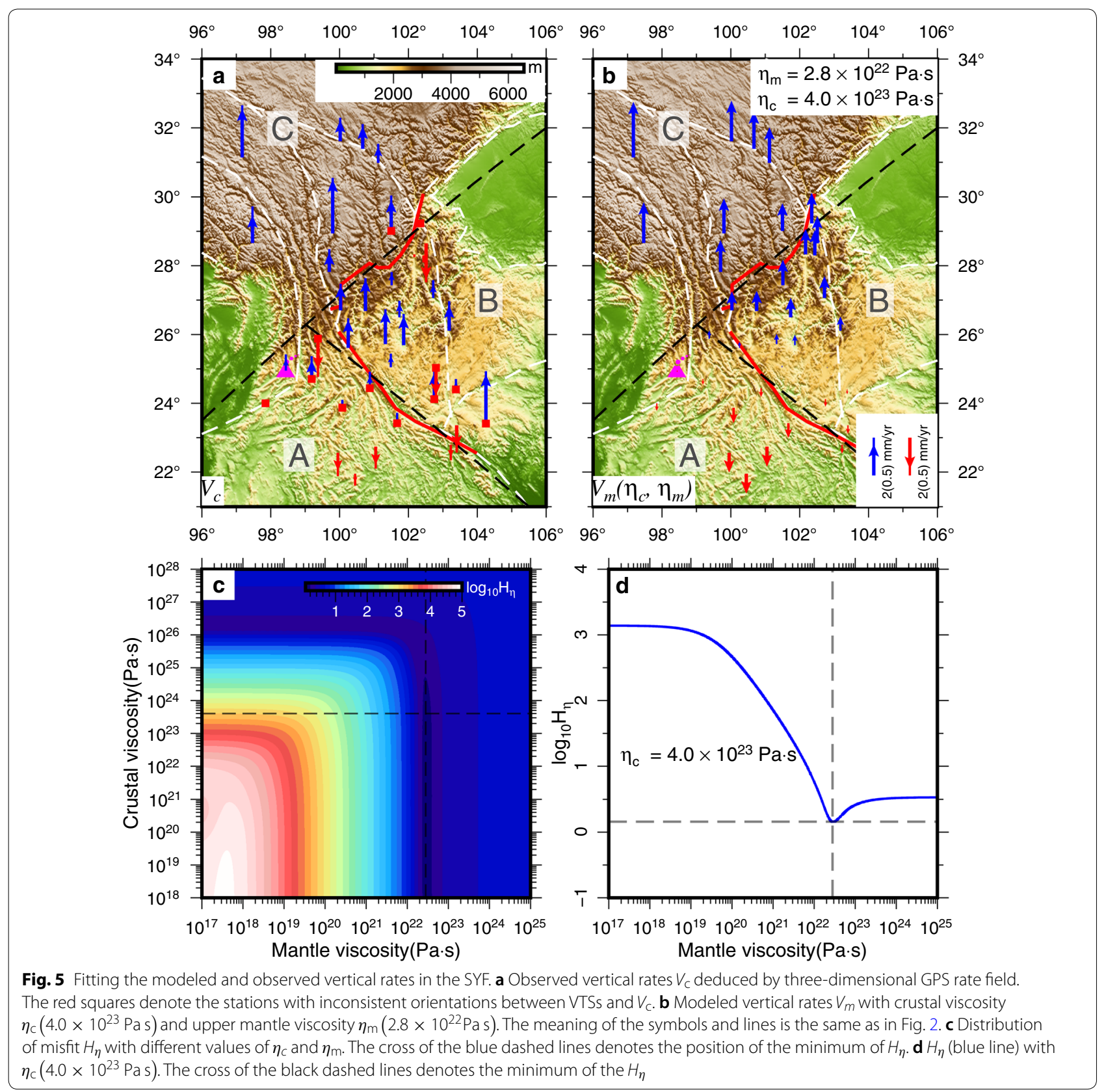

To illustrate the magnitude of vertical rates caused by different mass sources, we calculate the surface load vertical rates $V_{d}$ (Fig. 6) due to deposition rates in the Asian region (Métivier et al. 1999) by using spherical surface load theory (Farrell 1972; Wang et al. 2012) with the Preliminary Reference Earth Model (Dziewonski and Anderson 1981). The magnitude of $V_{d}$ is $0.01 \mathrm{~mm} /$ year, which is two orders of magnitude smaller than $V_{\mathrm{c}}$ (Fig. 6) and one order of magnitude smaller than $V_{g}$. Because the rate and extent of erosion are very difficult to recover, the deformation rates caused by erosion cannot be obtained accurately. Since the source of erosion should be distributed at the upstream of the rivers, in the high-altitude area, and should be greater than the corresponding places in section C (Fig. 6), it is reasonable to estimate that the magnitude of vertical rates $V_{e}$ caused by erosion would be less than $V_{d}$ in the SYF. As described above, $V_{g}$ includes $V_{d}, V_{e}$ and the vertical rates $\left(V_{w}\right)$ caused by water storage change. Thus, when the $V_{d}$ and $V_{e}$ are small, the $V_{w}$ will be the biggest in $V_{g}$.

In summary, the water storage change is the primary cause of the vertical rates due to surface mass migration. 


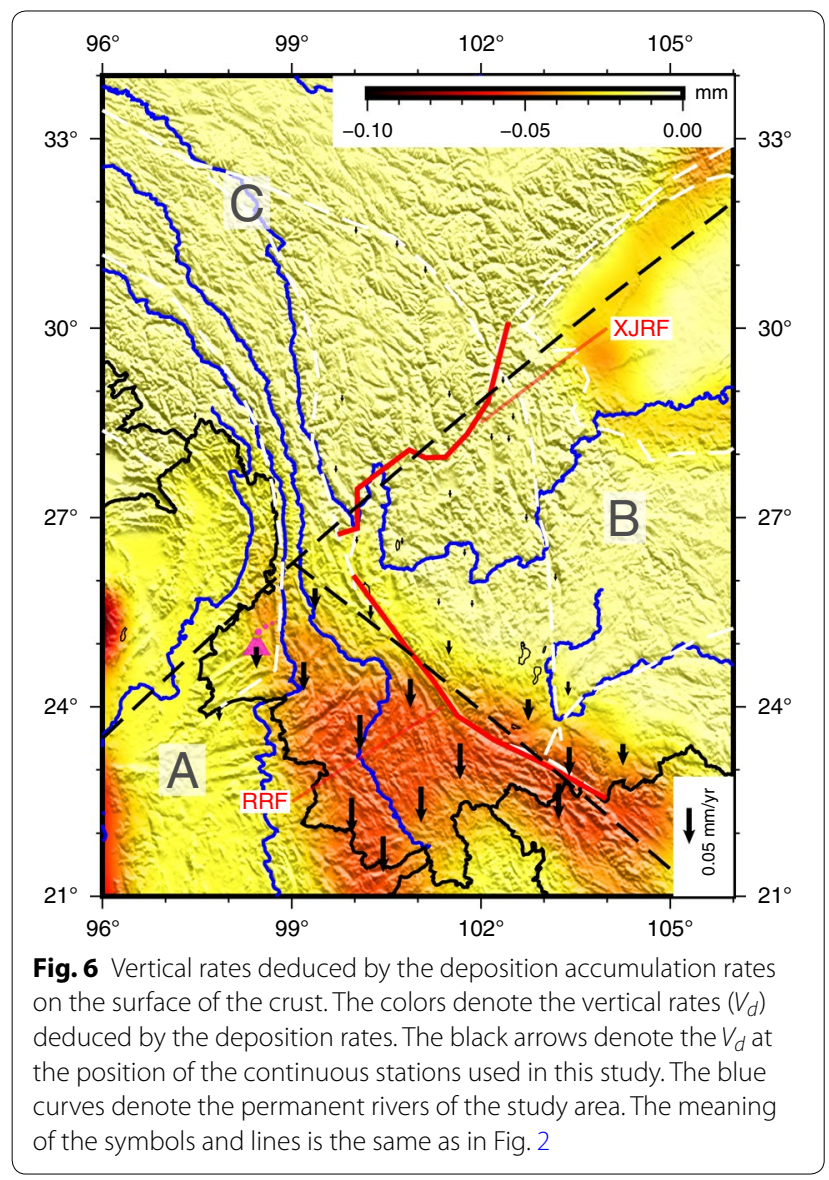

The magnitude of vertical rates caused by deposition, erosion and water storage changes is much smaller than $V_{\mathrm{c}}$, and the effects are eliminated by using GRACE data. Thus, the effect of surface mass migration can be ignored in this study.

\section{Vertical rates caused by deep dynamic activities}

The deep dynamic activities in this area include volcanic activity and channel flow. The seismic and geothermal evidence shows the presence of magma in the crust derived from the upper mantle in the Tengchong volcano field (TCVF) (Wang and Huangfu 2004; Wu et al. 2016), and GPS observations show that this area is uplifted (Fig. 2, magenta triangle). Thus, it is reasonable to conclude that the uplift of the TCVF is caused by the driving force from the upper mantle. According to the conclusion above, we exclude the data from the GPS stations near TCVF from $V_{\mathrm{c}}$ and search again for the optimal solution. However, the results do not change significantly.

Hao et al. (2016) inferred that channel flow in the lower crust has created southern subsidence with respect to the northern area in the SYF. Actually, channel flow is the result of continental convergence in which the lower crust is so weak that the upper crustal deformation is decoupled from the motion of the underlying upper mantle (Clark and Royden 2000; Royden et al. 1997). This indicates that if the upper crust and lower crust are coupled, the upper crust will be stretched with the motion of the lower crust. Therefore, the topography is changed during this process as well. As previously described, the channel flow model seems to be able to explain the southern subsidence by the stretching from north to south, but the uplift of the crust in the northern SYF cannot be explained by it (Fig. 3 in Clark and Royden 2000). Additionally, the specific distribution, dynamic source and movement mechanism of the channel flow are not completely clear. In particular, the distribution of the channel flow given by different studies (Bai et al. 2010; Bao et al. 2015; Liu et al. 2014; Qiao et al. 2018) has significant differences. Thus, it is impractical to quantitatively study crustal vertical movement caused by the channel flow.

According to the description above, surface mass migration and deep dynamic activities are not the main causes of the vertical movement in the SYF. Therefore, we find that the VTSs dominate the driving mechanism for the vertical movement in the SYF, and the escape of the crustal material in the Tibetan Plateau may cause the VTSs. Specifically, with the collision of the Indian and Eurasian plates, the Tibetan Plateau continues to uplift and results in the gradual accumulation of internal gravitational potential energy (GPE) (Flesch et al. 2001; Ghosh et al. 2006). The escape of the upper crustal materials due to the GPE from north to south in the SYF makes the lithosphere deviate from the equilibrium state, forms the current topography and Moho and decides the distribution of the VTSs.

\section{Conclusion}

In this study, we use three-dimensional GPS rates and a two-layer viscous model consisting of crust and upper mantle to explain the vertical deformation in the SYF. The results are summarized below:

1. The SYF area can be divided into three sections by XJRF and RRF, which both contain a normal fault component, and this is consistent with GPS observation. The average rates of the three sections have a step-like distribution with a step change of $1 \mathrm{~mm} /$ year, and the southern subsidence rate is about 1-2 $\mathrm{mm}$ /year with respect to the northern area confirming the previous study (Hao et al. 2016).

2. The fitting results between the rates deduced from three-dimensional GPS data and the rates calculated by the two-layer viscous model show that the viscosity of the upper mantle is about $2.8 \times 10^{22} \mathrm{Pas}$, and the viscosity of the crust is less than $1 \times 10^{25} \mathrm{~Pa}$. 
However, the lower limit of $\eta_{\mathrm{c}}$ is not obtained in this study.

3. Vertical deformation rates caused by deposition and erosion are one order of magnitude smaller than the vertical rates caused by the water storage change and two orders of magnitude smaller than the vertical rates from the GPS.

4. We find that the VTSs dominate the driving mechanism for the vertical movement in the SYF. However, considering the complex deformation in the SYF, observations of InSAR (interferometric synthetic aperture radar) and gravity data should be added to future studies to further validate the above conclusion.

\section{Abbreviations}

EHS: Eastern Himalayan syntaxis; GPS: Global positioning system; GRACE: Gravity recovery and climate experiment; InSAR: interferometric synthetic aperture radar; ITRF: International terrestrial reference system; LMS: Longmen Shan; LSC: least square collocation; RRF: Red River fault zone; SYF: Sichuan-Yunnan fragment; TCVF: Tengchong volcano field; VTSs: vertical tectonic stresses; XJRF: Xiaojin River fault zone.

\section{Authors' contributions}

Yawen She and Guangyu Fu developed the study and wrote the paper jointly. Both authors read and approved the final manuscript.

\section{Acknowledgements}

The authors are grateful for the shared data from Hao et al. (2016), Liang et al. (2013) and Pan et al. 2018). The authors thank two anonymous reviewers for their helpful comments and constructive suggestions. Maps and plots are created by the Generic Mapping Tools (GMT) (Wessel and Smith 1991).

\section{Competing interests}

The authors declare that they have no competing interests.

\section{Availability of data and materials}

The GPS data used by this study can be downloaded from the Web sites of the references (Hao et al. 2016; Liang et al. 2013; Pan et al. 2018). CRUST 1.0 data can be downloaded from https://igppweb.ucsd.edu/ gabi/crust1.html. LITHO 1.0 data can be downloaded from https://igppweb.ucsd.edu/ gabi/ litho1.0.html.

\section{Consent for publication \\ Not applicable.}

\section{Ethics approval and consent to participate}

Not applicable.

\section{Funding}

This work is supported by National Science Foundation of China: 41574071, 41331066, 41874003; Basic Research Projects of Institute of Earthquake Science, China Earthquake Administration: 2016IES010204; and Research Project of Hebei Earthquake Agency, China Earthquake Administration: DZ20170510054.

\section{Publisher's Note}

Springer Nature remains neutral with regard to jurisdictional claims in published maps and institutional affiliations.
Received: 14 August 2018 Accepted: 12 March 2019

Published online: 22 March 2019

\section{References}

Amante C, Eakins BWW (2009) ETOPO1-1 arc-minute global relief model: Procedures, data sources and analysis. NOAA technical memorandum NESDIS NGDC-24, 10(March), 25. https://doi.org/10.1594/PANGAEA.76961 5

Bai D, Unsworth MJ, Meju MA, Ma X, Teng J, Kong X et al (2010) Crustal deformation of the eastern Tibetan plateau revealed by magnetotelluric imaging. Nat Geosci 3(5):358-362. https://doi.org/10.1038/ngeo830

Bao X, Sun X, Xu M, Eaton DW, Song X, Wang L et al (2015) Two crustal lowvelocity channels beneath SE Tibet revealed by joint inversion of Rayleigh wave dispersion and receiver functions. Earth Planet Sci Lett 415:16-24. https://doi.org/10.1016/j.epsl.2015.01.020

Bills BG, Currey DR, Marshall GA (1994) Viscosity estimates for the crust and upper mantle from patterns of lacustrine shoreline deformation in the Eastern Great Basin. J Geophys Res Solid Earth 99(B11):22059-22086. https://doi.org/10.1029/94JB01192

Bürgmann R, Dresen G (2008) Rheology of the lower crust and upper mantle: evidence from rock mechanics, geodesy, and field observations. Annu Rev Earth Planet Sci 36(1):531-567. https://doi.org/10.1146/annurev.earth .36.031207.124326

Chen B, Liu J, Chen C, Du J, Sun Y (2015) Elastic thickness of the HimalayanTibetan orogen estimated from the fan wavelet coherence method, and its implications for lithospheric structure. Earth Planet Sci Lett 409:1-14. https://doi.org/10.1016/j.epsl.2014.10.039

Clark MK, Royden LH (2000) Topographic ooze: building the eastern margin of Tibet by lower crustal flow. Geology. https://doi.org/10.1130/00917613(2000)28<703:TOBTEM>2.0.CO;2

Deng Q, Zhang P, Ran Y et al (2003) Basic characteristics of active tectonics of China. Sci China Ser D 46(04):356-372

Dixon JE, Dixon TH, Bell DR, Malservisi R (2004) Lateral variation in upper mantle viscosity: role of water. Earth Planet Sci Lett 222(2):451-467. https ://doi.org/10.1016/j.epsl.2004.03.022

Dziewonski AM, Anderson DL (1981) Preliminary reference Earth model. Phys Earth Planet Inter 25(4):297-356. https://doi.org/10.1016/00319201(81)90046-7

England P, Molnar P (1997) Active deformation of Asia: from kinematics to dynamics. Science 278(5338):647-650. https://doi.org/10.1126/scien ce.278.5338.647

Farrell WE (1972) Deformation of the Earth by surface loads. Rev Geophys 10(3):761-797. https://doi.org/10.1029/RG010i003p00761

Flesch LM, Haines AJ, Holt WE (2001) Dynamics of the India-Eurasia collision zone. J Geophys Res Solid Earth 106(B8):16435-16460. https://doi. org/10.1029/2001JB000208

Fu G, She Y (2017) Gravity anomalies and isostasy deduced from new dense gravimetry around the Tsangpo Gorge, Tibet. Geophys Res Lett 44(20):10233-10239. https://doi.org/10.1002/2017GL075290

Gan W, Zhang P, Shen ZK, Niu Z, Wang M, Wan Y et al (2007) Present-day crustal motion within the Tibetan Plateau inferred from GPS measurements. J Geophys Res Solid Earth 112(8):1-14. https://doi.org/10.1029/2005J B004120

Gao S, She Y, Fu G (2016) A new method for computing the vertical tectonic stress of the crust by use of hybrid gravity and GPS data. Chin J Geophys 59(6):2006. https://doi.org/10.6038/cjg20160607 (in Chinese)

Ghosh A, Holt WE, Flesch LM, Haines AJ (2006) Gravitational potential energy of the Tibetan Plateau and the forces driving the Indian plate. Geology 34(5):321-324. https://doi.org/10.1130/G22071.1

Hao M, Freymueller JT, Wang Q, Cui D, Qin S (2016) Vertical crustal movement around the southeastern Tibetan Plateau constrained by GPS and GRACE data. Earth Planet Sci Lett 437:1-8. https://doi.org/10.1016/j. epsl.2015.12.038

Holt WE, Ni JF, Wallace TC, Haines AJ (1991) The active tectonics of the eastern Himalayan syntaxis and surrounding regions. J Geophys Res Solid Earth 96(B9):14595-14632. https://doi.org/10.1029/91JB01021

Karner GD (1982) Spectral representation of isostatic models. BMR J Aust Geol Geophys 7(1):55-62 
Kaufmann G, Amelung F (2000) Reservoir-induced deformation and continental rheology in vicinity of Lake Mead, Nevada. J Geophys Res Solid Earth 105(B7):16341-16358. https://doi.org/10.1029/2000JB900079

Kirby JF, Swain CJ (2008) An accuracy assessment of the fan wavelet coherence method for elastic thickness estimation. Geochem Geophys Geosyst. https://doi.org/10.1029/2007GC001773

Kirby JF, Swain CJ (2009) A reassessment of spectral teestimation in continental interiors: the case of North America. J Geophys Res Solid Earth 114(8):1-36. https://doi.org/10.1029/2009JB006356

Lambeck K, Smither C, Johnston P (1998) Sea-level change, glacial rebound and mantle viscosity for northern Europe. Geophys J Int 134(1):102-144. https://doi.org/10.1046/j.1365-246x.1998.00541.x

Laske G, Masters G, Ma Z, Pasyanos M (2013) Update on CRUST1. 0-a 1-degree global model of Earth's crust. In: Geophys. Res. Abstr (vol 15, p 2658). EGU General Assembly Vienna, Austria

Lau HCP, Mitrovica JX, Austermann J, Crawford O, Al-Attar D, Latychev K (2016) Inferences of mantle viscosity based on ice age data sets: radial structure. J Geophys Res Solid Earth 121(10):6991-7012. https://doi. org/10.1002/2016JB013043

Liang S, Gan W, Shen C, Xiao G, Liu J, Chen W et al (2013) Three-dimensional velocity field of present-day crustal motion of the Tibetan Plateau derived from GPS measurements. J Geophys Res Solid Earth 118(10):5722-5732. https://doi.org/10.1002/2013JB010503

Liu QY, Van Der Hilst RD, Li Y, Yao HJ, Chen JH, Guo B et al (2014) Eastward expansion of the Tibetan Plateau by crustal flow and strain partitioning across faults. Nat Geosci 7(5):361-365. https://doi.org/10.1038/ngeo2130

Lu R, Xu X, He D, John S, Liu B, Wang F et al (2017) Seismotectonics of the 2013 Lushan Mw6.7 earthquake: inversion tectonics in the eastern margin of the Tibetan Plateau. Geophys Res Lett 44(16):8236-8243. https://doi. org/10.1002/2017GL074296

Métivier F, Gaudemer Y, Tapponnier P, Klein M (1999) Mass accumulation rates in Asia during the Cenozoic. Geophys J Int 137(2):280-318. https://doi. org/10.1046/j.1365-246X.1999.00802.x

Milne GA, Davis JL, Mitrovica JX, Scherneck HG, Johansson JM, Vermeer M, Koivula $\mathrm{H}$ (2001) Space-geodetic constraints on glacial isostatic adjustment in fennoscandia. Science 291(5512):2381-2385. https://doi.org/10.1126/ science.1057022

Milne GA, Mitrovica JX, Scherneck H-G, Davis JL, Johansson JM, Koivula H, Vermeer M (2004) Continuous GPS measurements of postglacial adjustment in Fennoscandia: 2. Modeling results. J Geophys Res Solid Earth 109(B2):1-19. https://doi.org/10.1029/2003jb002619

Mitrovica JX, Forte AM (1997) Radial profile of mantle viscosity: results from the joint inversion of convection and postglacial rebound observables. J Geophys Res Solid Earth 102(B2):2751-2769. https://doi.org/10.1029/96JB03175

Molnar P, Tapponnier P (1975) Cenozoic tectonics of Asia: effects of a continental collision. Science 189(4201):419-426. https://doi.org/10.1126/scien ce.189.4201.419

Moritz H (1980) Advanced physical geodesy. Herbert Wichmann, Karlsruhe, Germany

Nadai A (1963) Theory of flow and fracture of solids, vol 2. McGraw-Hill, New York

Pan Y, Shen W-B, Shum CK, Chen R (2018) Spatially varying surface seasonal oscillations and 3-D crustal deformation of the Tibetan Plateau derived from GPS and GRACE data. Earth Planet Sci Lett 502:12-22. https://doi. org/10.1016/..epsl.2018.08.037

Pasyanos ME, Masters TG, Laske G, Ma Z (2014) LITHO1.0: an updated crust and lithospheric model of the Earth. J Geophys Res Solid Earth 119(3):21532173. https://doi.org/10.1002/2013JB010626

Patriat P, Achache J (1984) India-Eurasia collision chronology has implications for crustal shortening and driving mechanism of plates. Nature 311(5987):615-621. https://doi.org/10.1038/311615a0

Peltier WR (1998) Postglacial variations in the level of the sea: implications for climate dynamics and solid-earth geophysics. Rev Geophys 36(4):603689. https://doi.org/10.1029/98RG02638

Peltier WR, Argus DF, Drummond R (2015) Space geodesy constrains ice age terminal deglaciation: the global ICE-6G_C(VM5a) model. J Geophys Res Solid Earth 2015(120):450-487. https://doi.org/10.1002/2014JB0111 76. Received

Pollitz FF (2003) Transient rheology of the uppermost mantle beneath the Mojave Desert, California. Earth Planet Sci Lett 215(1-2):89-104. https:// doi.org/10.1016/S0012-821X(03)00432-1
Qiao L, Yao H, Lai YC, Huang BS, Zhang P (2018) Crustal structure of Southwest China and Northern Vietnam from ambient noise tomography: implication for the large-scale material transport model in SE Tibet. Tectonics 37(5):1492-1506. https://doi.org/10.1029/2018TC004957

Royden LH, Burchfiel BC, King RW, Wang E, Chen Z, Shen F, Liu Y (1997) Surface deformation and lower crustal flow in Eastern Tibet. Science 276(5313):788-790. https://doi.org/10.1126/science.276.5313.788

Royden LH, Burchfiel BC, Van Der Hilst RD (2008) The geological evolution of the Tibetan plateau. Science 321(5892):1054-1058. https://doi. org/10.1126/science. 1155371

Rychert CA, Shearer PM (2009) A global view of the lithosphere-asthenosphere boundary. Science 324(5926):495-498. https://doi.org/10.1126/scien ce. 1169754

She Y, Fu G, Wang Z, Liu T, Xu C, Jin H (2016) Gravity anomalies and lithospheric flexure around the Longmen Shan deduced from combinations of in situ observations and EGM2008 data. Earth Planets Space 68(1):163. https:// doi.org/10.1186/s40623-016-0537-7

She Y, Fu G, Wang Z, Gao Y (2017) Vertical tectonic stress in eastern margin of Bayan Har block revealed by gravity and terrain data. Chin J Geophys 60(6):2480. https://doi.org/10.6038/cjg20170635 (in Chinese)

Strehlau J, Meissner R (1987) Estimation of crustal viscosities and shear stresses from an extrapolation of experimental steady state flow data. Compos Struct Dyn Lithosphere Asthenosphere Syst 16:69-87. https://doi. org/10.1029/GD016p0069

Tapponnier P, Zhiqin X, Roger F, Meyer B, Arnaud N, Wittlinger G, Jingsui Y (2001) Oblique stepwise rise and growth of the Tibet Plateau. Science 294(5547):1671-1677. https://doi.org/10.1126/science.105978

Walcott RI (1970) Flexural rigidity, thickness, and viscosity of the lithosphere. J Geophys Res 75(20):3941-3954. https://doi.org/10.1029/JB075i020p 03941

Wang CY, Huangfu G (2004) Crustal structure in Tengchong volcano-geothermal area, western Yunnan, China. Tectonophysics 380(1-2):69-87. https:// doi.org/10.1016/j.tecto.2003.12.001

Wang YZ, Wang EN, Shen ZK, Wang M, Gan WJ, Qiao XJ et al (2008) GPSconstrained inversion of present-day slip rates along major faults of the Sichuan-Yunnan region, China. Sci China Ser D Earth Sci 51(9):1267-1283. https://doi.org/10.1007/s11430-008-0106-4

Wang H, Xiang L, Jia L, Jiang L, Wang Z, Hu B, Gao P (2012) Load love numbers and green's functions for elastic Earth models PREM, iasp91, ak135, and modified models with refined crustal structure from Crust 2.0. Comput Geosci 49:190-199. https://doi.org/10.1016/j.cageo.2012.06.022

Watts AB (2001) Isostasy and flexure of the lithosphere. Cambridge University Press, Cambridge

Wessel P, Smith WHF (1991) Free software helps map and display data. Eos Trans Am Geophys Union 72(41):441-446. https://doi.org/10.1029/90EO0 0319

Wu Y, Jiang Z, Yang G, Wei W, Liu X (2011) Comparison of GPS strain rate computing methods and their reliability. Geophys J Int 185(2):703-717. https ://doi.org/10.1111/j.1365-246X.2011.04976.X

Wu T, Zhang S, Li M, Qin W, Zhang C (2016) Two crustal flowing channels and volcanic magma migration underneath the SE margin of the Tibetan Plateau as revealed by surface wave tomography. J Asian Earth Sci 132:25-39. https://doi.org/10.1016/j.jseaes.2016.09.017

Xu Z, Wang F, Jiang L, Xu S, Tang L (2018) The depth of Moho interface and crustal thickness in Sichuan-Yunnan region, China. Seismol Geol 40(6):1318-1331. https://doi.org/10.3969/j.issn.0253-4967.2018.06.009 (in Chinese)

Yamagiwa S, Miyazaki S, Hirahara K, Fukahata Y (2015) Afterslip and viscoelastic relaxation following the 2011 Tohoku-oki earthquake (Mw9.0) inferred from inland GPS and seafloor GPS/acoustic data. Geophys Res Lett 42(1):66-73. https://doi.org/10.1002/2014GL061735

Yin A, Harrison TM (2000) Geologic evolution of the Himalayan-Tibet orogen. Annu Rev Earth Planet Sci 28:211-280. https://doi.org/10.1080/01947 641003598252

Zhang P, Deng Q, Zhang G, Ma J, Gan W, Min W et al (2003) Active tectonic blocks and strong earthquakes in the continent of China. Sci China Ser D 46(October):13-24. https://doi.org/10.1360/03dz0002 